\title{
Passage Variations: An Elliptical History of Migration in Eleonas
}

\author{
Abstract \\ The hypnotic repetition of passages between white containers in the refugee camp in \\ Eleonas, in Athens, heightens the temporality experienced by the refugees in the \\ camp - a sense of life in temporary suspension or perpetual deferment. Passage \\ Variations uses eight images taken from a film that documents the passageways in \\ the camp and their variation owed to human inhabitation. The stills are accompanied \\ by a textual collage of immigrants' testimonies, literary excerpts on the subject of \\ migration and some instances in the history of the area as a notional edge of the city. \\ The linear, arduous and open-ended migrant journey is contrasted to the \\ monotonous and closed spatial experience of the camp. The essay that follows \\ reflects on these accounts and negotiates the temporal and geographical distance \\ between them - a newly found space of tolerance amid reconciled fragments of \\ histories, experience and collective memory.
}

Keywords

Eleonas refugee camp; Athens; migration; visual anthropology; film essay;

Ektoras Arkomanis is a filmmaker and a senior lecturer in architectural history and theory in the Cass School of Art, Architecture and Design, in London Metropolitan University. His research revolves around cities and film. He also publishes essays on the history of architecture. He is currently researching and shooting his second feature film, A Season in Eleonas, which centres on the themes of migration and work/labour in the area of Eleonas in Athens. 


\section{En route}

They sent us to an olive grove near the sea and asked us to stay there until the morning. At six they brought the boat and told us to get in. We were 70 people, we had 25-26 children on the boat. After ten or fifteen minutes you can't see anything else - sky and water. The sea and the sky, nothing else. ${ }^{1}$

Those two infinites, the sea and the sky, were then restored in her eyes again. [...] A light wind blew from the stern, wrinkling the waves. The boat was dancing lightly on the liquid pitch. [...] And is it up to humans to suffer or not to suffer? $[\ldots]$

She was contemplating the sail she had attempted not knowing where she was heading, and was recalling that other wayfaring, the paradoxical, the numinous one. ${ }^{2}$ 
Arrival

[...] a gravel road called Ploutonos St. As you make your way, you'll come across Orfeos St. These chthonic names have an ambiguous significance here. Life thrives in this area. And at the same time you get the impression of a landscape that has died: you are in the place where the city banishes all its waste, all that is useless and unwanted. ${ }^{3}$

We live here, ten Kurdish families. Thirty people. We are Muslims. We don't have water or electricity. Our children don't go to school. We're always afraid because we don't have permits. Some are scavengers, others work in construction sites, another works in a petrol station, some don't have work. We have good relationships with people, we have no complaints. We have Greek names too, to make things easier. ${ }^{4}$

After being humiliated one continues the manuscript of identity. $^{5}$ 


\section{Passage variations}

It's an old story from the previous century about my father and me.

The same old story from yesterday morning about me and my son.

It's called "Survival Strategies

and the Melancholy of Racial Assimilation."

It's called "Psychological Paradigms of Displaced Persons,"

called "The Child Who'd Rather Play than Study". ${ }^{6}$

In the time of Athens

the girls would laugh in the doorways of squat little houses all the same

(as in the poor quarters of Rio);

houses along avenues filled, at the time,

with the fragrance (you couldn't remember the name) of lindens.

[...]

It's wartime; and if the girls laugh it's because they are holy. ${ }^{7}$ 
Passage Variations unfolds on Christmas Eve in the refugee camp in Eleonas, in Athens. The experience of walking through the passages formed by the rows of trailers, once internalised, triggers my contemplation on migration through oral testimonies, literary accounts and the history of the area of Eleonas, which has seen other, earlier migrations.

These passages have their own spatial and mental attributes. They are modern laid out as a grid of outdoor corridors and prefabricated metallic emergency shelters that cater for basic human needs. They are also traditional thresholds, in the sense of connecting private quarters to public spaces: the information desk, the launderette, the plaza, a small football pitch, etc. The camp is of course conceived as a space of tolerance, not segregation. ${ }^{8}$ Refugees stay there voluntarily in order to cover their needs of food and shelter, as well as to get help with their paperwork before continuing their travel in Europe. ${ }^{9}$ They participate in various gatherings and activities: language or skills classes delivered by volunteers, supervised playgroups for children, physical exercise groups, performances and other communal events on Saturday evenings under the big tent. As destinations, these sanctioned events can make the movement and transitions in the camp deterministic rather than wilful. And when you deviate from the expected routes, more often than not you end up by the perimeter wall, which looms you back into the grid and exacerbates the feeling of being adrift, which is painfully familiar to the refugees. The images (Figures 1-7), which are stills from a film in progress, focus on the hypnotic repetition of containers and passages as a spatial analogue to the temporality experienced by the refugees in the camp: life in a state of brief suspension or perpetual deferment. ${ }^{10}$

In contrast, the writing follows the more linear and open-ended procedure of a refugee's journey: embarkation, arrival, settling. Each part is rendered through a different voice - contemporary or from the past, speaking in poetry or prose - which fragments the previous story, or at least re-draws the setting. What emerges is an elliptical narrative. The geographical, temporal and cultural distance between the disparate accounts becomes a mental space carved out of the existing histories, 
memories and literary records - a canvas for contemplation on the entangled present and ubiquity of migration.

The story begins with an inhabitant of the camp, a Syrian refugee, recalling setting out from somewhere on the coast of Turkey, on his journey to Greece. This narrative displacement - speaking of an elsewhere and another time, while being here, today - is a form of mentally resisting or reversing the journey. An anthropologist might understand the journey as a series of places and experiences that conveniently lead to the present. For the refugee the rupture is not complete; its effect is unabating because the present settings and changes are never really experienced as separate from the past. The narration preserves a memory of human frailty set off against the vastness of the natural elements - an image of peril in an unnamed location where sovereign law and power cannot be exercised but their impact is most strongly felt. In this liminal setting - far from where the political life (bios) takes place, and under conditions with no semblance to ordinary life (zoe) - we can apprehend Agamben's concept of 'bare life' as life exposed to death. The figure of the refugee embodies the homo sacer, included in the modern nation-state only in the form of an exception. ${ }^{11}$

The Syrian refugee's interview is juxtaposed with an excerpt from a Greek novel about a migrant's journey, which was written almost a century and a half ago and uncannily recounts a similar memory, the moment when the land is no longer discernible and one is left only with the uncertainty of the sea and the sky. This kind of translation - from first- to third-person narration - can be hazardous but Trinh T. Minh-ha stresses that it can be rewarding too, because both tropes (reality and fantasy) have a role to play in "questioning the limits set on what is known as 'common' and 'ordinary' in daily existence, offering thereby the possibility of an elsewhere-within-here or -there." ${ }^{12}$ In this case the landscape does not bode precarity; rather, it assuages the protagonist's musings on the human condition. The 'soft' border of the sea, hardened in autobiographical testimony, is liquefied again by literary form. 
We arrive at Eleonas as described by a journalist in the late 1980s. This is the time when two hitherto parallel histories - of work and migration - converge to give Eleonas its distinct character. Small businesses, such as tile-makers, furnaces, bag makers, etc., had existed in Eleonas since the nineteenth century, scattered between the crops and the wild fields. In the early 1920s around 300,000 Greek immigrants from Turkey settled in Athens, most of them in uninhabited or underdeveloped areas around the city with ample space but no community infrastructure to speak of. ${ }^{13}$ Wooden shacks and adobe houses replaced olive trees, vines and crops in the landscape, and in the following decades factories, tanneries and other outlets proliferated, but without proper planning in place. By the 1980s Eleonas had become the industrial zone of the city, well within the modern conglomeration of Athens, yet still excluded from the official city plan.

From around that time onwards, new cycles of migration, from Albania, Africa and the Middle East gave rise to a particular economy around migrant labour, characterized by lax regulations and self-licensing on the part of many business proprietors. The Kurdish immigrant's interview two decades later attests the continual failure of the state and society to properly integrate the immigrant workforce of Eleonas over the past half century. This brings the story up to the next watershed: the global financial crisis, after which the industrial activity in Eleonas declined, many factories were abandoned, and their workers took up selling goods in the scavengers' markets of Eleonas or found other similar day-to-day jobs. Meanwhile, following the wars and instability in the Middle East, the refugee camp was set up in 2015. Even though it has offered much needed relief, it has also reinforced the perception of Eleonas as the place in the city where unwanted elements end up.

A year earlier, I had by chance filmed the then empty lot where the refugee camp would be installed. To the east, over a wall covered by a long graffiti, the Athenian Acropolis was discernible in the distance. ${ }^{14}$ Perhaps that juxtaposition alone was the reason for filming there, but in my mind its potency has since diminished. Instead, 
the footage of the only other person around on that morning, an Ethiopian migrant who lived in a dumped trailer at the fringe of a rill, and was putting up a washing line between two trees, has become my reference to that 'before' time. Now I revisit it with the hindsight that in the months that followed many refugees were moved from the Greek islands to this site in Eleonas and elsewhere in the mainland. Three years later, my more deliberated filming in the camp is suffused with these earlier impressions: the once open views across the lot; that single washing line that antedated the dozens of clothes lines now in the camp; and the graffiti, still there, but hidden behind trailers that reveal only small fragments.

A similar reduction occurs as I extract still images from the film. The initial aim behind the visual and textual quotations may have been to preserve certain moments and details, but they become more poignant as reminders that the narratives at our disposal are elliptical to begin with; that these stories first played out elsewhere - on the Greek islands, in other Balkan countries, Turkey, the Mediterranean Sea, North and Central Africa, and the Middle East - and we can only access them through testimony.

Paradoxically, changing medium can have a restorative effect. The sounds recorded in the film are not present here, so they are replaced in my mind by others' memories recounted in poetry and storytelling, that linger on as I observe things around in the camp. Mostly material things: accessories, colours, textures, shoes and unwanted furniture dumped outside the trailers - an inventory of signs of inhabitation that provide variation in these otherwise homogenous passageways; or a form of cataloguing anything that future events might promote from incidental to noteworthy. Therefore, the technical variation in the stills is kept to a minimum. All passages are photographed in the same manner in order to assert the planned symmetry of this urban settlement and its spatial hierarchy, which begins with the main thoroughfares, continues with the narrower 'corridors' to the back streets, and ends with the personal element: adjustments and interruptions. 
The peculiarity of material interventions and human conduct allow a drift from 'bare life' towards the reconstitution of natural life. Agamben used the concentration camp as a paradigm of the abject shattering of natural life by sovereign violence, partly because it is a closed system, in which everydayness is obliterated. ${ }^{15}$ In the case of the refugee camp in Eleonas the state has set up a zone where the corporeal exception of the refugee is not fulfilled - after all, one can exit from it at will. The exclusion is real - the wall of the compound confirms that - but not all encompassing, precisely because the everydayness of life not only persists within that border, but it acquires its own vivid detail. Some of these details are not centreof-frame but become noticeable only when the eye begins to explore against the composition. Then there are exchanges witnessed from the distance, like a brief handshake, out of focus. After a while these moments no longer appear mundane, but as part of a quietly unfolding play of human behaviours and concerns.

More voices enter. They are not related to the refugee camp or Eleonas specifically; they speak about migration, Athens (incidentally) and childhood (importantly). These excerpts do not complete the story; rather they acknowledge that the same tale of displacement is perpetually rewritten with new protagonists and circumstances. I think that this is what Li-Young Lee expresses in his poem when he quotes what are presumably sample titles of studies, which approach the problem by renaming it with jargon from various disciplines, and in the process come close to eviscerating it. Nevertheless, this denotes a departure from the personal element in the first lines of Lee's poem. And so we move on, to the girls in Pasolini's poem, who are the girls of Athens, generically (or perhaps of the poor quarters in Rio, the poem says), 'holy' but unnamed; and to the face of the girl in the refugee camp in Eleonas, which is blurred. The stakes are raised above individual concerns - the child here embodies the hereditary nature of the problems of assimilation, identity and our attitudes towards the marginal.

\section{Acknowledgments}

I wish to thank my unnamed informant interviewed in the Eleonas refugee camp, the workers and volunteers in the camp who assisted this research, Serafeim Arkomanis 
for his contribution to the filming and photography, Joseph Kohlmaier for the design and presentation of this piece, Aleks Catina and Colin O'Sullivan for their useful observations, and last but most, Zoi E. Ropaitou-Tsapareli for generously providing a copy of her invaluable research on Eleonas and its neighbouring areas.

\section{References}

Agamben, Giorgio. Homo Sacer: Sovereign Power and Bare Life. Stanford, Calif.: Stanford University Press, 1998

Arkomanis, Ektoras. "Invented Memories: Notes on Filming Industrial Ruins in Eleonas, Athens," Architecture and Culture 3, no. 1 (2015)

Giannakopoulos, Georgios S (ed). Refugee Greece: Photographs from the Archives of the Centre for Asia Minor Studies. Athens: A. G. Leventis Foundation/Centre for Asia Minor Studies, 1992.

Lee, Li-Young. Behind My Eyes: Poems. London: W. W. Norton \& Company, 2009.

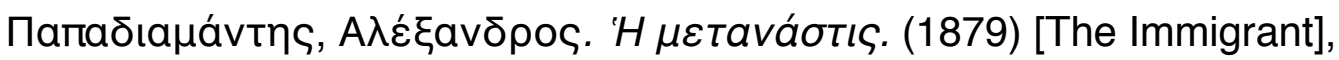
http://www.papadiamantis.org/works/57-novel/75-01-01-h-metanastis-1879, accessed 26/12/2017

Pasolini, Pier Paolo, James Ivory, and Stephen Sartarelli. The Selected Poetry of Pier Paolo Pasolini. A bilingual edition. Chicago London: The University of Chicago Press, 2014.

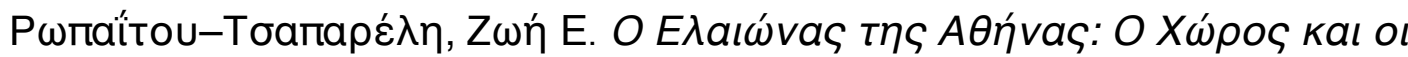

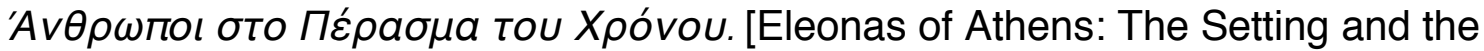

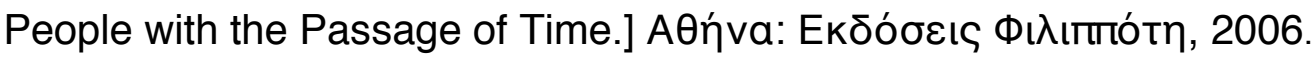

Sharma, Prageeta. Infamous Landscapes. 1. ed. Albany, NY: Fence Books, 2007. 
Trinh T. Minh-Ha. Elsewhere, Within Here. London: Routledge, 2010.

\section{Endnotes}

${ }^{1}$ Unnamed informant: Syrian refugee in the Eleonas refugee camp. Interviewed by the author, December 24, 2017.

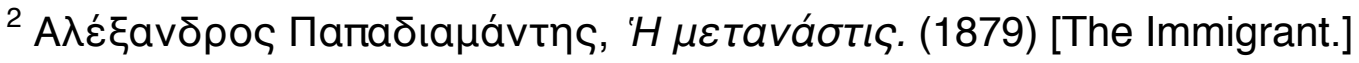
http://www.papadiamantis.org/works/57-novel/75-01-01-h-metanastis-1879, accessed 26/12/2017. Own translation.

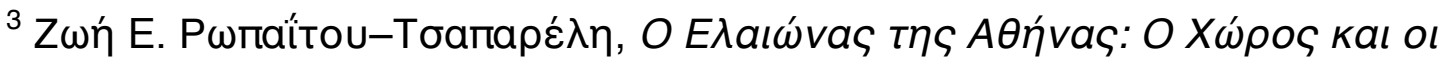

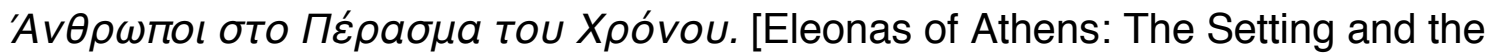

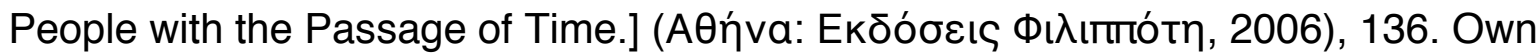
translation.

${ }^{4}$ Ibid., 322. Informant: Veli Rabi Asari, resident of Eleonas, c. 2006 (precise date of interview unknown). Own translation.

${ }^{5}$ Prageeta Sharma, Infamous Landscapes. 1. ed. (Albany, NY: Fence Books, 2007), 57.

${ }^{6}$ Li-Young Lee, Behind My Eyes: Poems (London: W. W. Norton \& Company, 2009), 28-29.

${ }^{7}$ Pier Paolo Pasolini, James Ivory, and Stephen Sartarelli, The Selected Poetry of Pier Paolo Pasolini; A bilingual edition. (Chicago London: The University of Chicago Press, 2014), 392-394. 
${ }^{8}$ The Eleonas refugee camp is a government-run project. It is supervised by the Greek Ministry for Migration Policy, and operates in collaboration with NGOs and various teams of volunteers.

Hellenic Republic, Ministry for Migration Policy. Accessed November 3, 2018. http://www.immigration.gov.gr/en_US/web/guest/elleniki-metanasteutiki-politiki

${ }^{9}$ The number of refugees sheltered in the camp changes on a daily basis. In general, it has increased relatively steadily since the camp was established, from approx. 700 in 2015, to approx. 2300 presently (2018).

Ilena Kritikou and Menelaos Myrillas, Greece's only refugee camp. Al-Jazeera. Last modified September 30, 2015.

https://www.aljazeera.com/indepth/inpictures/2015/09/greece-refugees-camp150928101923759.html

The National Herald, "Eleonas Refugees in Athens Share Their Plight with TNH". The National Herald. Last modified June 6, 2017.

https://www.thenationalherald.com/165105/tnh-visits-eleonas-refugee-camp-athens/, Project Elea, “Eleonas Refugee Camp”. Project Elea. Accessed November 3, 2018 https://projectelea.org/about-us/

UNHRC (The UN Refugee Agency), “Greece - UNHRC”. Last modified January 2017. https://data2.unhcr.org/en/documents/download/53941

${ }^{10}$ The vast majority of refugees in the camp have plans for continuing their journey in Europe and settling in other countries. The government and the NGOs aim to keep the average stay time in the camp at three days for individuals, and at two weeks for families. This period, however, is often prolonged due to processing an individual's papers and issuing a status for them. There are cases of refugees who remain in the camp for longer than a year.

${ }^{11}$ Giorgio Agamben, Homo Sacer: Sovereign Power and Bare Life (Stanford, Calif.: Stanford University Press, 1998), 4-8, 76-80. 
${ }^{12}$ Trinh T. Minh-Ha, Elsewhere, Within Here (London: Routledge, 2010), 28.

${ }^{13}$ Greek immigrants arrived from Turkey as a result of a series of historic events: the Turkish War of Independence (1919-1923); the abolition of the Ottoman Empire (1922) and the founding of the Republic of Turkey (1923) - all of which led to atrocities against the settled migrant populations in both Greece and Turkey, and culminated in the population exchange between the two states (1923). For a vivid photographic record on the resettlement of refugee populations in Greece at the time, accompanied by transcribed oral testimonies see: Georgios S.

Giannakopoulos, ed., Refugee Greece: Photographs from the Archives of the Centre for Asia Minor Studies (Athens: A. G. Leventis Foundation/Centre for Asia Minor Studies, 1992).

${ }^{14}$ Ektoras Arkomanis, "Invented Memories: Notes on Filming Industrial Ruins in Eleonas, Athens." Architecture and Culture 3, no. 1 (2015): 57-64. This essay details the beginning of my filming in Eleonas, in 2014. It outlines the history of the area from ancient times to the present and provides a more specific account on its recent history of work, industrial ruins, dereliction and informalities.

${ }^{15}$ Agamben, Homo Sacer, 81-86, 107-116. 